\title{
The Potential of Blockchain in Building Construction
}

\author{
Zakaria Dakhli $\odot$, Zoubeir Lafhaj * and Alan Mossman * \\ Civil Engineering, Ecole Centrale de Lille, 59651 Villeneuve d'Ascq, France; zakaria.dakhli@centralelille.fr (Z.D.); \\ alanmossman@mac.com (A.M.) \\ * Correspondence: zoubeir.lafhaj@centralelille.fr
}

Received: 8 February 2019; Accepted: 26 February 2019; Published: 5 April 2019

\begin{abstract}
Construction customers want more complex facilities delivered faster and at a lower cost. Transaction costs account for a significant proportion of each new or refurbished facility (a 2017 report from the Infrastructure Client Group in the UK suggests as high as 50\%), yet they contribute no value to the customer. Blockchain is being suggested as a way to reduce transaction costs by eliminating the need for intermediaries to build trust as a prerequisite for successfully executed agreements. This study first describes the thinking that underpins blockchain technology, outlining how it works, and the potential limitations of the technology. Second, using a case study, reviews the potential cost savings from the use of blockchain for a real estate company. The results reveal a potential cost savings from blockchain deployment at $8.3 \%$ of the total cost of residential construction, with a standard deviation of $1.26 \%$. Third, we explore the implications, risks and applications of blockchain technology for improving flow in the end-to-end design and construction process and we identify opportunities for future research on blockchain applications in construction.
\end{abstract}

Keywords: blockchain; construction; BIM; transactional costs; lean construction

\section{Introduction}

Some construction activities create value for one or more of the construction delivery system's customers. Some do not. Some of those that don't are currently necessary to enable the delivery of the value that customers want. The aim of this paper is to begin to explore whether blockchain might be a way to reduce the time, money and efforts that create no value for customers.

As Turk has stated, construction is a collaborative process [1]. Collaboration around any economic activity requires trust. Most people do not trust blindly-they want verification and reassurance that the other party is worthy of their trust, and in commercial settings they often buy that reassurance from intermediaries, middlemen and women, go-betweens, and matchmakers who they feel are trustworthy. There are lots of intermediaries in all sectors [2,3]. Keiser has shown how leadership and culture encourage more trusting relationships in construction [4].

Intermediaries take time to do what they do (e.g., it takes days for a credit card payment to appear in your account) and they charge a fee for the service (the vendor only receives some of the money that is charged to your credit card account). Generally, intermediaries gather information about you-in order to secure the deal, they need to convince the other party, or the other party's intermediary, that you too are trustworthy.

All of these actions take time, effort and money yet, create no value for customer(s), though they may currently be necessary for value to be created. That's the way the world works now. What if it was no longer necessary to use some or all these intermediaries? How else can we trust? One suggestion is by using a blockchain. 


\section{Literature Review on Blockchain}

Blockchain is a distributed database (ledger) that maintains a list of records (of transactions, information, Internet Protocol (IP), etc.). These records are called blocks. Each block has a timestamp, a link to the previous block, and contains the history of every block (transaction) that came before it (down to the second it was created.) This 'chains' the blocks together. The whole system is end-to-end encrypted. Every transaction is linked to a unique cryptographic signature (called a hash function) that is easy to verify and nearly impossible to falsify because the blockchain is hosted by a growing network of (personal) computers; each computer is a 'node' in the system and each node monitors every other node on a continuous basis. The system grows with each transaction and can become global. Your laptop or desktop could be a node. It is like a Google Doc but with one major difference:

- You can view it;

- You can add to it, but;

- You cannot change the information that is already there.

Each node checks its local record (block) with every other block in the chain. If it discovers a discrepancy it looks for consensus and, if necessary, replaces itself with the consensus. What this means is that to change the record it is necessary to simultaneously change $>50 \%$ of the nodes in the system. That is not impossible, but it is very difficult and becomes increasingly difficult as the length of the chain grows. Blockchains generally have the following five elements:

- Cryptography: The use of a variety of cryptographic techniques including cryptographic one-way hash functions, Merkle trees, and public key infrastructure (private-public key pairs).

- Peer to peer (P2P) network: A network for peer discovery and data sharing in a peer-to-peer fashion.

- Consensus mechanism: An algorithm that determines the ordering of transactions in an adversarial environment (i.e., assuming that not every participant is honest).

- Ledger: A list of transactions bundled together in cryptographically linked 'blocks'.

- Validity rules: A common set of rules of the network (i.e., what transactions are considered valid, how the ledger gets updated, etc.) [5].

and these three features [6]:

- Distributed, which makes it harder to hack or tamper with, but not impossible. If enough nodes decide to collude then blocks comprising of transactions can, in theory, be reversed.

- Consensus-based, which makes it harder to hack or tamper with - and

- Requires less trust; a blockchain can only reduce the need for trust. At the bare minimum, trust must be placed in the underlying cryptography. The chain is only as good as the data input, so trust in the quality of the data that others provide is also essential. In the case of a permissioned network (Permissioned blockchain networks allow the network to appoint a group of participants who are given the express authority to validate blocks of transactions and to participate in the consensus mechanism. The second key difference is the ability to restrict who can create smart contracts and/or transact on the blockchain network. (https://monax.io/explainers/permissioned_blockchains/)) trust must be placed in the operator(s) and/or the validators.

Blockchains have many benefits - cutting out intermediaries, reducing costs and time, lowering the barriers to entry in several sectors, providing security in technological systems [1], They also. have limitations:

- A 51\% attack: if more than half of the computers working as nodes to service the network tell a lie, the lie will become the truth. This is called a ' $51 \%$ attack' and was highlighted by Satoshi Nakamoto (2008) when he launched Bitcoin [7]. Blockchains employ cryptography for authentication, permission enforcement, integrity verification, and other areas. The mere application of cryptography, however, does not automatically make the system more secure 
per se. The system may be more resilient as data storage and permissions are distributed but compromising the private keys of some network participants could give attackers full access to the shared database, including the ability to reverse a transaction history.

- Data quality: If a blockchain is used as a database [8], the information going into the database needs to be of high quality. The data stored on a blockchain is not inherently trustworthy, so events need to be recorded accurately in the first place. The phrase 'garbage in, garbage out' holds true in a blockchain system of record, just as with a centralized database. Blockchains are particularly well suited for the transfer of assets or data native to the respective blockchain. A blockchain cannot assess whether a given input from the 'outside world' is accurate/true or not. If the input is inaccurate or wrong, the blockchain will just treat it as any other input and consider all transfers involving the input as valid as long as certain conditions are met. Attention needs to be paid to data validity and integrity.

- Blockchains: like all distributed systems, are not so much resistant to bad actors as they are 'antifragile'; In order to reap the full benefits, this requires a robust network of users with a widely distributed grid of nodes [9]. There are some discussions and debates about whether this a fatal flaw for some permissioned blockchain projects (https:/www.coindesk.com/information/ blockchains-issues-limitations/). As well as a limitation, this can be a strength.

- Data storage and bandwidth requirements: the current limited size of blocks makes it slow to write transactions. The current block size for a chain that started in 2008 is over 180 GB (Nov18) [10].

- Limit to the number of transactions per block:

- Audit requirement: the integrity of a blockchain demands that anyone can audit the chain back to the first block, a measure that increases the time and cost of doing an audit [11].

- Scalability: according to Microsoft, the Bitcoin network consumes enough energy to power more than 1.3 million households. Bitcoin is one example of the blockchain application.

- Adaptability: once confirmed, the history of transactions cannot be reversed in a blockchain. However, with the agreement of all parties, agreements can be changed.

- Regulation: regulations cannot keep up with advances in technology. Regulations are expected to take decades to set adequate standards and policies for the democratization of blockchain.

- Technological immaturity: Relatively immature technology, origins in 2008 (Nakamoto 2008).

- Privacy: there are limitations to the privacy offered by current blockchain technology.

Some actions to implement the blockchain in the construction sector have already begun. For instance, real estate development has implemented a bitcoin payment system, including smart contracts [12]. For general contractors, a blockchain can also be deployed via intelligent contracts to facilitate interactions with stakeholders (government, social landlord, real estate developer, suppliers, subcontractors, insurers, etc.) to increase the transparency of physical and financial flows as well as to facilitate the transmission of information.

Some research states that certain aspects of the construction contract cannot be fully intelligent and the best that can be achieved in the short to mid-term is a semi-automated position [13].

\section{Research Methodology}

In order to show the potential of a blockchain in the building construction project, data were collected from a real estate development company. The research is presented in the form of a case study, and follows the case study research method according to (Yin, 2013) [14].

\subsection{Presentation of the Real Estate Developer Case Study}

The real estate developer takes the initiative for the realization of the property and assumes responsibility for the coordination of operations involved in the study, execution, and procurement of construction programs to users. The real estate developer is responsible for monitoring the design and implementation of real estate programs. This includes the choice of land, the definition of the 
program, the composition of the project management team (responsible for carrying out the projects and controlling the execution of works), the award of construction contracts, the monitoring of the construction, and the sale of the property.

The real estate company selected for this case study develops expertise in commercial and residential real estate. It specializes in the acquisition, development, and management of residential properties $(+70 \%$ of its activity concerns residential real estate management). The company is present in all regions of France with a strong concentration of activity in Northern France and the Paris region.

The company mainly develops residential 'programs', which are then put out to tender for construction companies. The real estate company is therefore considered as a customer for construction companies.

\subsection{Data Collection}

This study looked at 56 residential building programs distributed across France from the real estate developer's database. The financial cost sheets of those programs were collected. The program's cost is distributed as in Table 1. This study considers only the perspective of the real estate developer, from the phase after land acquisition.

Table 1. Cost structure for a building housing real estate program.

\begin{tabular}{cc}
\hline \multicolumn{2}{c}{ Total Cost } \\
\hline \multirow{2}{*}{ 1. Construction } & Works contract \\
\cline { 2 - 2 } 2. Management & Risk \\
\cline { 2 - 2 } 3. Sales administration & Pdoject Management \\
\cline { 2 - 2 } & Commercial costs \\
\hline
\end{tabular}

The hypothesis is that blockchain in Construction cuts intermediaries and contributes to control risks. The impact of the blockchain in this case study is assessed as follow:

$$
\frac{\text { Risk }+ \text { Project Management }+ \text { Sales support }}{\text { Total Cost }}
$$

The result of this equation is a percentage that approximates the potential cost savings from blockchain deployment in the case of this research article: Housing building construction.

\section{Results and Discussion}

Table 2 reveals the average, median, and standard deviation of the case study's samples.

The potential cost savings from blockchain deployment is estimated at $8.3 \%$ of the total cost of the housing building construction, with a standard deviation of $1.26 \%$.

Table 2. Average, median, and standard deviation of the case study's samples.

\begin{tabular}{ccc}
\hline Average (\%) & Median (\%) & Standard Deviation (\%) \\
\hline 8.30 & 8.00 & 1.26 \\
\hline
\end{tabular}

The results of the savings, mainly from the transactional costs rooted in the conventional organization, are shown in Table 2. 
We also collected data on the real estate's margin on the building housing programs. The average net margin is $6 \%$ with a $2.5 \%$ standard deviation. The latter is high because of the inherent risk associated with each program. The potential cost savings from a blockchain is higher than the current net margin.

\subsection{Discussion and Synthesis of the Role of Blockchain in Construction}

The blockchain is, above all, a structured database. Today, it is mainly used to record financial decisions, transactions and agreements. While transaction costs account for a significant proportion of construction costs [15], it can also be applied to physical flows (e.g., product movement), and information flows (e.g., a particular action is activated).

The construction sector is first and foremost a sector dominated by social interactions and the human aspect. Our experience and years of research works with construction companies suggest that one predominant challenge of the sector is the search and identification of the Right information at the Right time in the Right place and especially to the Right person. In this sense, the blockchain has a big role to play by highlighting the flow of information.

\subsubsection{Implications}

Using a smart contract, if a predefined event or series of actions triggers a consequential action, such as a payment - there is no need for an invoice as that creates no value for anyone. Decentralized autonomous organizations (DAOs) - are entire sets of long-term smart contracts that can replace decision making processes of a business organization, and reduce management-level staff significantly. Transaction records and program rules are maintained on the blockchain and thus transparent to the owners of the blockchain (Buterin, 2014). Two important elements must therefore be brought together for a smart contract in construction:

- A definition of the precise tasks of the act of building.

- A listing of all the possible variants related to a given task. To clarify this point, it will be assumed that the tiler was absent, and the electrician's work was therefore delayed. The intelligent contract must take into account all scenarios.

These two points currently constitute the DNA of the work of the site manager. The latter mainly deals with the definition, corrections, and updating of tasks to remedy daily unforeseen events on site. Much of its work includes negotiating to find common ground between subcontractors and other stakeholders, in order to justify and fill in ambiguous interfaces between contractors (who does what, who will take charge of the execution? etc.)

The intelligent contract (contract automation) in the construction phase will therefore remain a myth until these two points are addressed. This is where lean construction can be leveraged.

\subsubsection{The Notion of Value}

In the context of lean thinking, value is defined by the customer. Value is what the customer wants (for a longer discussion of value see e.g., (Salvatierra-Garrido et al., 2012) [16]. Defining who the customer is, or the customers are, is critical to success in construction. Depending on where in the construction supply chain a supplier sits, the customer could be the next-trade-in-line, the end-user of the facility, the purchaser, the municipality, a neighbor of the facility being constructed or some combination. For example, if I am a plasterer, the tiler or the painter may be my next-trade-in-line; the quality of my plastering affects their ability to deliver quality work that end-users will see and feel. As a painter getting exactly the right shade of blue to create a calm and relaxing atmosphere in the dentists waiting room affects both dental patients and the work of the dentist. These are relatively simple examples. There are many potential customers for construction outputs.

In construction, given the multiplicity of customers for each process, in order to meet the Conditions of Satisfaction [17] for any activity, each supplier has to negotiate what "value" means to 
all relevant stakeholders and to build agreement. If there is no agreement, there is potential for rework. If there is agreement, the supplier knows what her or his customers want, and it is much easier for the supplier to deliver what is required without rework. One reason that architects spend long hours taking and understanding the brief is because there are many customers that need to be satisfied. If it is possible to accurately document that complexity and to measure each requirement (e.g., with a performance specification), then it is possible to capture the requirement in a blockchain and link it to a smart contract.

\subsubsection{The Construction Value Chain}

A value stream is the set of actions that creates the value sought by a customer or customers [18]. As we said in the introduction, some activities in the construction value stream create value for one or more of the system's customers, and some do not. Some of those that don't are currently necessary to enable the delivery of the value that customers want. The aim of this paper is to begin to explore whether blockchain might be a way to reduce the time, money and efforts that create no value for customers (even if they make money for some actors, such as intermediaries, in the construction space). What is critical is that these activities create no value for any customer.

One common process for project delivery is Design-Bid-Build. After the client's brief, the approach is initiated through programming and studies where the lead designer and the design team develops the concept and then the detailed design of the project. The tendering phase follows, and the selected construction company starts the work. Finally, the delivery of the final product (building or other type of construction) finalizes the construction project.

The project owner could be a real estate developer, social landlord, etc. Their customers are the tenants \&/or buyers of the residential units and associated commercial space (if any). The construction company's (direct) customer is the developer. If the construction company uses subcontractors, the direct customer is the construction company and the next-trade-in-line as well as the developer and their customers. Members of the design team are customers and suppliers to each other and are suppliers to developer, the constructor, the sub-contractors and the constructor's own detail designers. Ultimately their designs will enhance or detract from the developer's reputation. This is a complex system and the flows of money. Transaction costs follows the black arrows. This means that, for example, the subcontractor is paid by the general contractor and the latter is paid by the client. The general contractor pays the subcontractor and the latter pays its suppliers. Transactions are not only about money. By definition, a transaction cost is a cost incurred in making an economic exchange, cost of doing business. A contract involves transactions. An agreement is the result of many transactions; so is collaboration. There are other relationships that are equally if not more important that are not illustrated in Figure 1. Those are the relationships, the collaborations between trades. Currently these rely on trust, and they breakdown whenever anyone feels blamed for anything. These are vital relationships.

The act of constructing becomes even more complex as it involves several actors throughout the construction value chain. Thus, identifying direct and indirect clients is important (for example, who uses the structural plans being developed, directly and indirectly?). As a result, non-value added tasks arise throughout this long-, time-, and location-based value chain.

Figure 2 presents our view of the transaction costs after deploying the blockchain in construction. Intermediaries are reduced and the value flows smoothly across stakeholders. We identified two types of intermediaries in construction:

- Intermediaries inherent to the construction value chain: Cost consultants/QS, labor-only sub-contractors, client rep. (who stands between client and teams), project managers, accountants, and auditors. Another type of intermediary is when a subcontractor pays the general contractor, and after that the client pays the general contractor for the work done.

- Intermediaries outside the construction value chain: Banks, lawyers, courts, and the government. 


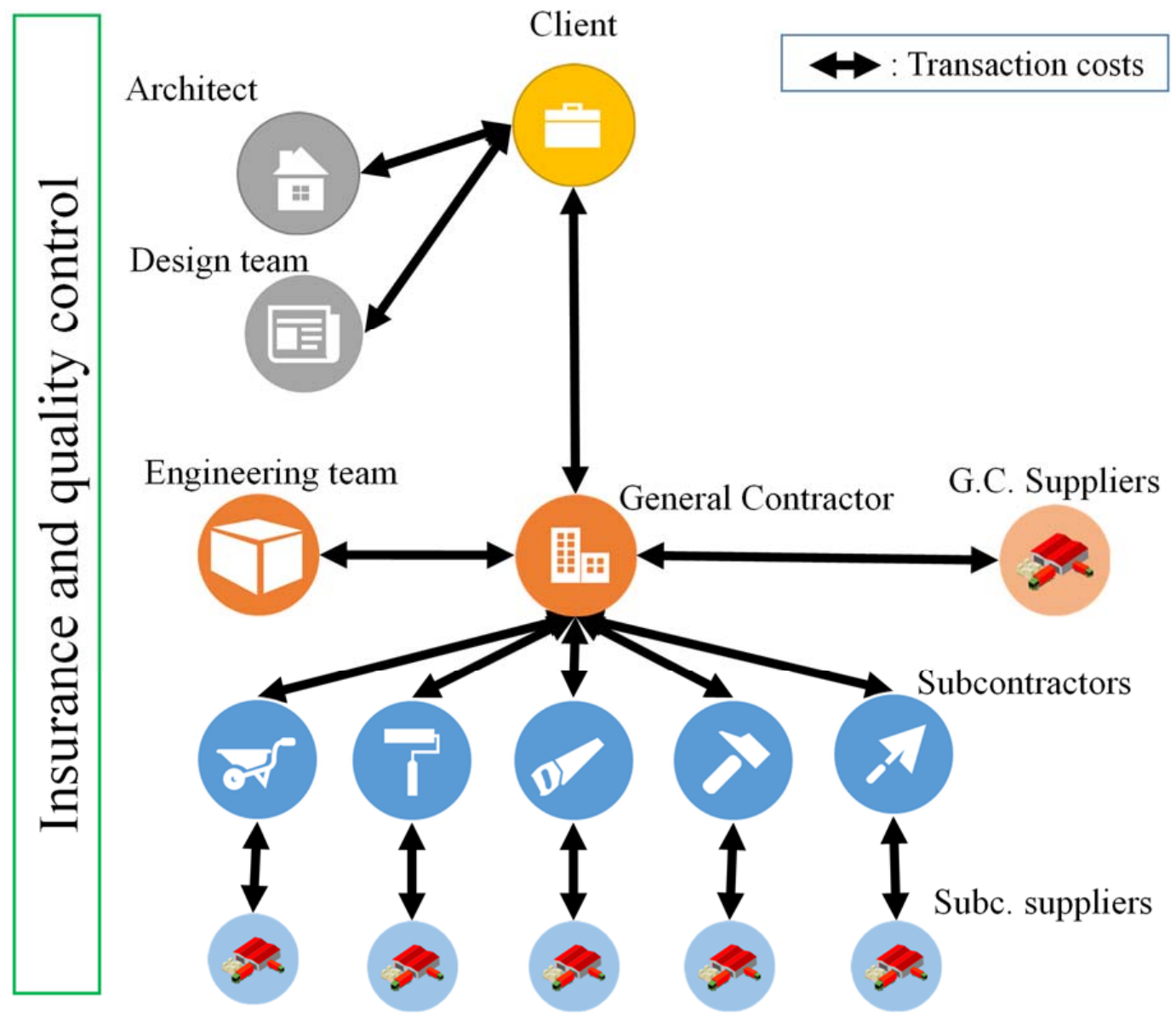

Figure 1. The contractual relationships and the flows of money

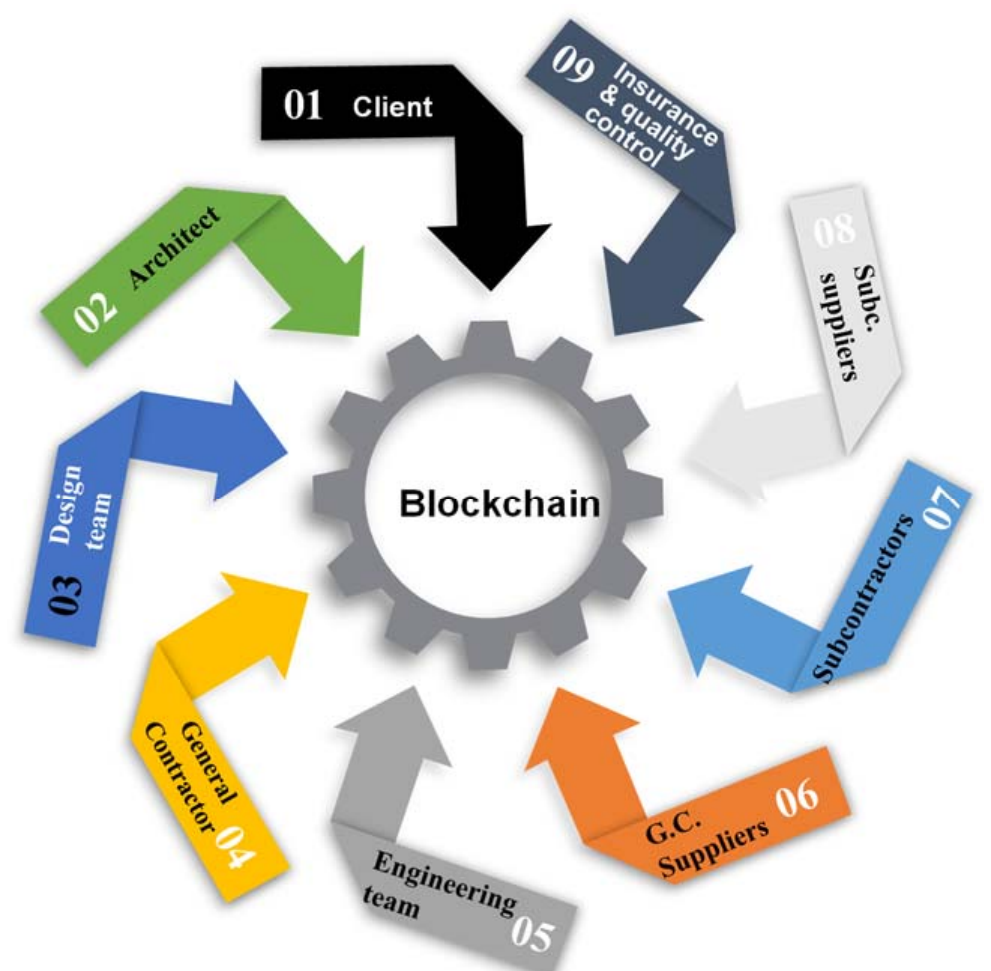

Figure 2. Blockchain-based construction. 


\section{Conclusions}

The motivation for this article comes from the multitude of research projects that diagnose the considerable number of non-value activities that shape the construction sector. Those non value activities stem from the nature and type of transactions that shape construction.

A blockchain network has the following key characteristics:

- Consensus: For a transaction to be valid, all participants must agree on its validity.

- Provenance: Participants know where the asset came from and how its ownership has changed over time because it maintains a strong and secure digital signature.

- Immutability: No participant can tamper with a transaction after it has been recorded to the ledger. If a transaction is in error, a new transaction must be used to reverse the error, and both transactions are then visible, thus providing an easy audit trail for big companies.

- Finality: A single, shared ledger provides one place to go to determine the ownership of an asset or the completion of a transaction, thus providing a great contract management system between the involved parties.

A case study was realized to provide an estimation of the potential impact, in terms of cost, of the blockchain technology for a real estate developer. A total of 56 building housing programs from the real estate developer's database concern this study and are distributed in different regions across France. The results revealed a potential cost savings from blockchain deployment at $8.3 \%$ of the total cost of the housing building construction, with a standard deviation of $1.26 \%$. Future research should focus on validating the hypothesis considered in this study and providing a framework to assess the impact of the blockchain in construction. This framework will probably depend on the stakeholders across the construction value chain.

Author Contributions: Z.L. conceptualized the idea, Z.D. conducted the literature search and the instruments collection, Z.D. and A.M. drafted the manuscript. Z.L. supervised the whole process, Z.L. reviewed the collected instruments, Z.L., Z.D. and A.M. critically reviewed the content of the manuscript.

Funding: This research received no external funding.

Conflicts of Interest: The authors declare no conflict of interest.

\section{References}

1. Turk, Ž.; Klinc, R.Ž. Potentials of Blockchain Technology for Construction Management. Procedia Eng. 2017, 196, 638-645. [CrossRef]

2. Keiser, J.A. Leadership and Cultural Change: Necessary Components of a Lean Transformation. In Proceedings of the 20th Annual Conference of the International Group for Lean Construction, San Diego, CA, USA, 18-20 July 2012.

3. Fung, P.K.; Chen, I.S.; Yip, L.S. Relationships and performance of trade intermediaries: An exploratory study. Eur. J. Mark. 2007, 41, 159-180. [CrossRef]

4. Janssen, M.; Sol, H.G.M. Evaluating the role of intermediaries in the electronic value chain. Internet Res. 2000, 10, 406-417. [CrossRef]

5. Hileman, G.; Rauchs, M.G. Global Blockchain Benchmark Study. Cambridge, 2017. Available online: https://cdn.crowdfundinsider.com/wp-content/uploads/2017/09/2017-Global-BlockchainBenchmarking-Study_Hileman.pdf (accessed on 8 February 2019).

6. Taylor, P.J.; Dargahi, T.; Dehghantanha, A.; Parizi, R.M.; Choo, K.K.R. A systematic literature review of blockchain cyber security. Digital Commun. Networks 2019. [CrossRef]

7. Nakamoto, S. Bitcoin: A Peer-to-Peer Electronic Cash System. 2008. Available online: https://s3.amazonaws.com/academia.edu.documents/54517945/Bitcoin_paper_Original_2.pdf? AWSAccessKeyId=AKIAIWOWYYGZ2Y53UL3A\&Expires $=1551242712 \&$ Signature $=Z U 4 \mathrm{cZ0} \%$ 2BjBdcoTC087\%2BJyYagFsCk\%3D\&response-content-disposition=inline\%3B\%20filename\%3DBitcoin_A_ Peer-to-Peer_Electronic_Cash_S.pdf (accessed on 8 February 2019). 
8. Atlam, H.F.; Wills, G.B. Technical aspects of blockchain and IoT. In Role of Blockchain Technology in IoT Applications; Elsevier: Amsterdam, The Netherlands, 2018; pp. 1-39.

9. Mohsin, A.H.; Zaidan, A.A.; Zaidan, B.B.; Albahri, O.S.; Albahri, A.S.; Alsalem, M.A.; Mohammed, K.I. Blockchain authentication of network applications: Taxonomy, classification, capabilities, open challenges, motivations, recommendations and future directions. Comput. Stand. Interfaces 2018. [CrossRef]

10. Global Market for Blockchain Technology 2016-2021 Statistic. 2019. Available online: https://www.statista. com/statistics/647231/worldwide-blockchain-technology-market-size/ (accessed on 21 February 2019).

11. Ali, M.; Nelson, J.; Shea, R.; Freedman, M.J. Bootstrapping Trust in Distributed Systems with Blockchains. 2016. Available online: https://www.usenix.org/system/files/login/articles/login_fall16_10_ali.pdf (accessed on 21 February 2019).

12. Veuger, J. Trust in a viable real estate economy with disruption and blockchain. Facilities 2018, 36, $103-120$. [CrossRef]

13. Mason, J. Intelligent Contracts and the Construction Industry. J. Leg. Aff. Disput. Resolut. Eng. Constr. 2017, 9, 04517012. [CrossRef]

14. Yin, R.K. Case Study Research: Design and Methods, 5th ed.; Sage Publications Inc.: Thousand Oaks, CA, USA, 2013.

15. Institution of Civil Engineers. From Transactions to Enterprises A New Approach to Delivering High Performing Infrastructure Infrastructure Client Group. 2017. Available online: https://www.majorprojectsknowledgehub.net/resources/from-transactions-to-enterprises-a-newapproach-to-delivering-high-performing-infrastructure/ (accessed on 21 February 2019).

16. Salvatierra-Garrido, J.; Pasquire, C.; Miron, L. Exploring Value Concept Through the IGLC Community: Nineteen Years of Experience. In Proceedings of the 20th Annual Conference of the International Group for Lean Construction, San Diego, CA, USA, July 2012.

17. Flores, F. Conversations for Action and Collected Essays: Instilling a Culture of Commitment in Working Relationships; CreateSpace: Scotts Valley, CA, USA, 2012; p. 138.

18. Womack, J.P.; Jones, D.T. Lean Thinking: Banish Waste and Create Wealth in Your Corporation; Free Press: New York, NY, USA, 1996. 